\title{
The Opportunities and Challenges of Silica Nanomaterial for Atherosclerosis
}

This article was published in the following Dove Press journal:

International Journal of Nanomedicine

\author{
Xuan Sha ${ }^{1,2}$ \\ Yue Dai ${ }^{1,2}$ \\ Xiaoxi Song ${ }^{1,2}$ \\ Siwen Liu ${ }^{1,2}$ \\ Shuai Zhang ${ }^{1,2}$ \\ Jingjing $\mathrm{Li}^{1,2}$
}

'Department of Radiology, Affiliated Hospital of Xuzhou Medical University, Xuzhou, Jiangsu, People's Republic of China; ${ }^{2}$ School of Medical Imaging, Xuzhou Medical University, Xuzhou, Jiangsu, People's Republic of China
Correspondence: Jingjing Li Department of Radiology, Affiliated Hospital of Xuzhou Medical University, Xuzhou, Jiangsu, People's Republic of China

Tel +865I683262623

Email qingchao0124@163.com

\begin{abstract}
Atherosclerosis (AS) as the leading cause of cardiovascular and cerebrovascular events has been paid much attention all the time. With the continuous development of modern medical drug treatment, surgical treatment, interventional treatment and other methods, the mortality rate of AS has shown a downward trend, while the morbidity rate is still increasing. Oral lipid-lowering or anti-inflammatory drugs are generally used for early AS, but the relatively low accumulation efficiency in lesions and the unavoidable side effects required researchers to develop more effective drug delivery approaches for the therapy of AS. Mesoporous silica nanoparticles as nanocarrier for drug delivery have received extensive attentions due to their flexible size, high specific surface area, controlled pore volume, high drug loading capacity and excellent biocompatibility. Series of good reviews about the mesoporous silica nanoparticles loaded drugs for cancer therapy have been well documented. However, their roles as nanocarrier for drug delivery to treat AS have few reports. In this review, the applications and challenges of mesoporous silica nanomaterials in the field of the diagnosis and therapy of AS have been summarized. The classification, synthesis, formation mechanism, surface modification and functionalization of mesoporous silica nanomaterials which were closely related to the theranostic effect of AS have also been included. Last but not the least, the future prospects' suggestions of mesoporous silica nanomaterial-based drug delivery system for AS are also provided.
\end{abstract}

Keywords: mesoporous silica, nanomaterials, diagnosis, drug delivery, atherosclerosis

\section{Introduction}

Cardio/cerebrovascular disease (CVD) is one of the main reasons for the increase of global mortality and AS has been considered to be the main pathological basis for inducing cardio/cerebrovascular disease. ${ }^{1}$ AS is a chronic inflammatory vascular disease $^{2}$ coming from the excessive and unregulated scavenger receptor-mediated internalization of oxidized low-density lipoprotein (oxLDL) in macrophages and their accumulation on the arterial wall to form lipid-rich plaques. ${ }^{3}$ Currently, the main treatments of AS are drug treatment and surgical treatment. ${ }^{4-6}$ Drug treatments such as blood lipid-lowering drugs, anti-inflammatory drugs, anti-platelet drugs, or thrombolytic drugs are generally preferred for patients with early AS or AS without severe symptoms. ${ }^{4-6}$ However, the relatively low accumulation efficiency of drugs at the lesion and the side effects associated with long-term use limit its wider clinical application. With the continuous improvement of surgical procedures such as recanalization, reconstruction or bypass transplantation, as well as interventional treatment such as intravascular vascular bypass and stent placement, the cure rate of AS is significantly increased. But the occurrence of complications such as postoperative vascular restenosis and 
unsatisfactory long-term patency rates requires researchers to develop more effective methods to treat $\mathrm{AS}^{7}$

With the rapid development of nanotechnology, nanocarrier-based drug delivery systems have gradually attracted widespread attention. Nanocarrier-based drug delivery system can not only make up for the shortcomings of general drugs such as short circulation time, poor stability, low bioavailability and systemic toxic reaction, but also target the lesion and control the release rate of the drug to improve the therapeutic effect. ${ }^{8}$ At present, researchers have developed a large number of organic or inorganic nanomaterials for drug delivery to treat various diseases, such as liposomes, ${ }^{9-12}$ polymer micelles, ${ }^{13-16}$ gold nanoparticles, ${ }^{17-19}$ carbon nanotubes, ${ }^{20-22}$ quantum dots, ${ }^{23-25}$ metal oxides, ${ }^{26,27}$ and mesoporous silica. ${ }^{28,29}$ Compared with other nanomaterials, mesoporous silica has been widely used in the construction of nanoplatforms for drug delivery due to its flexible size, high specific surface area, controlled pore volume, high drug loading capacity, high biocompatibility, good hydrothermal stability, and surface chemical modification. ${ }^{30,31}$ Currently, various functional mesoporous silica drug delivery systems have been developed for the treatment of various tumors, and a series of good reviews about the drug loading mesoporous silica nanomaterials for cancer therapy have been well documented. ${ }^{28,30-34}$ However, their roles to load drugs for AS have few reports. In this article, we summarized the classification, synthesis, formation mechanism, surface modification and functionalization of mesoporous silica nanomaterials as nanocarriers for drug delivery. Furthermore, their fate for the applications in the diagnosis and treatment of AS is also reviewed. Finally, the future prospects, challenges and suggestions of mesoporous silica nanomaterial-based drug delivery system for AS are commented (Figure 1).

\section{Classification, Synthesis, Formation Mechanism, Surface Modification and Functionalization of Mesoporous Silica Nanomaterials as Nanocarrier for Drug Delivery Classification of Mesoporous Silica}

Mesoporous silica is a type of inorganic polymer nanomaterials with a pore size between 2 and $50 \mathrm{~nm}$ and possesses a series of excellent properties such as high specific surface

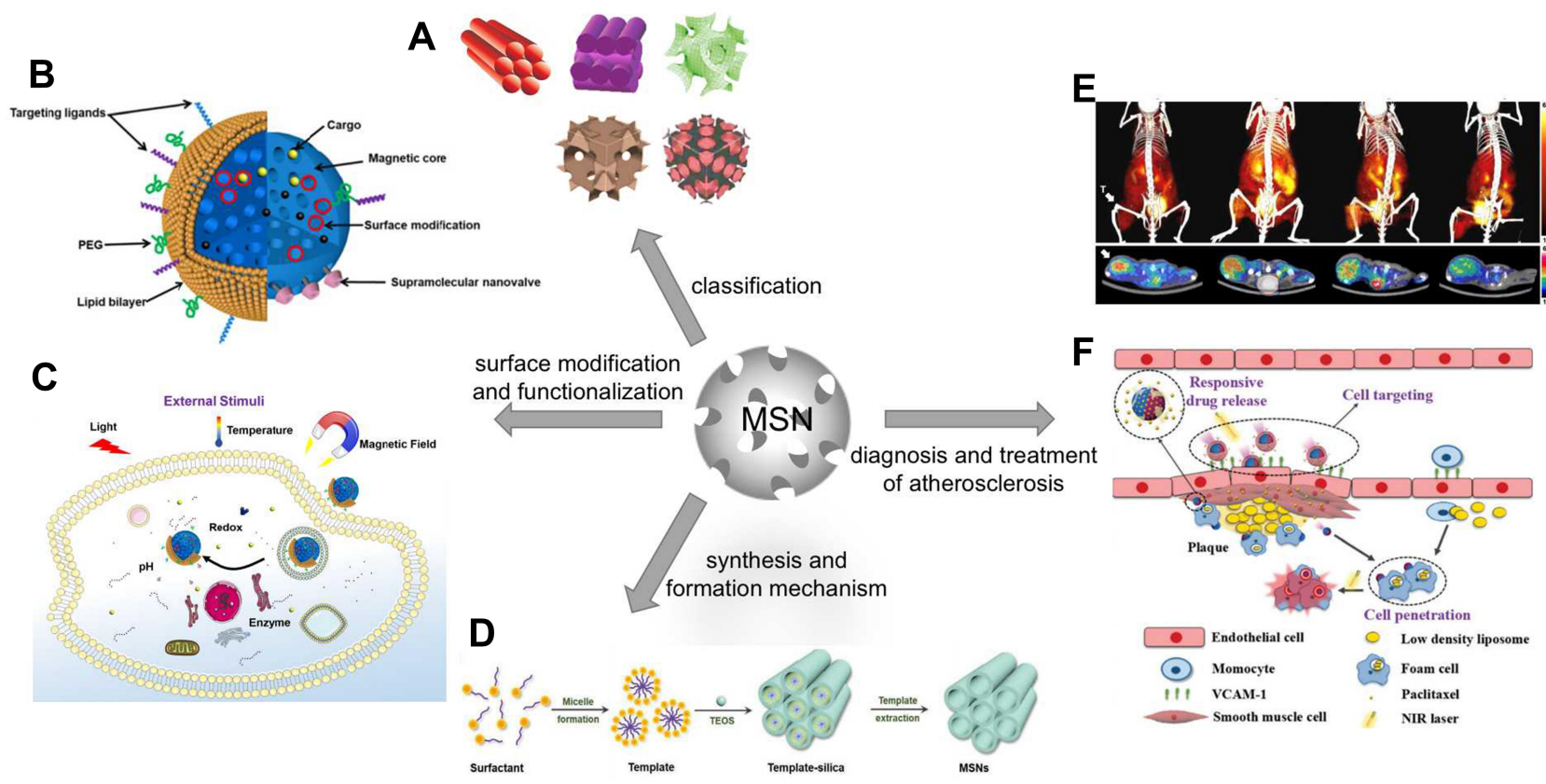

Figure I Schematic illustration of the classification (A), surface modification and functionalization (B and C), synthesis and formation mechanism (D), and application of mesoporous silica nanomaterials (E and $\mathbf{F}$ ) in this review.

Notes: (A) Reproduced from Narayan R, Nayak UY, Raichur AM, et al. Mesoporous Silica Nanoparticles: A Comprehensive Review on Synthesis and Recent Advances. Pharmaceutics. 2018;10(3):I18-166. Creative Commons license and disclaimer available from http://creativecommons.org/licenses/by/4.0/legalcode. ${ }^{45}$ (B, C) Li Z, Zhang Y, Feng N. Mesoporous silica nanoparticles: synthesis, classification, drug loading, pharmacokinetics, biocompatibility, and application in drug delivery. Expert Opin Drug Deliv. 2019;16(3):219-237, reprinted by permission of the publisher (Taylor \& Francis Ltd, http://www.tandfonline.com). ${ }^{44}$ (D) Kankala RK, Han YH, Na J, et al. Nanoarchitectured Structure and Surface Biofunctionality of Mesoporous Silica Nanoparticles. Adv Mater. 2020;32(23), reprinted by permission of the publisher (Taylor \& Francis Ltd, http:// www.tandfonline.com) ${ }^{87}$ (E) Reprinted from Biomaterials, 199, Jeong HJ, Yoo RJ, Kim JK, et al. Macrophage cell tracking PET imaging using mesoporous silica nanoparticles via in vivo bioorthog onal F- 8 labeling. 32-39, copyright (2019), with permission from Elsevier. ${ }^{74}$ (F) Huang Y, Li T, Gao W, et al. Platelet-derived nanomotor coated balloon for atherosclerosis combination therapy. J Mater Chem B Mater Biol Med. 2020;8(26):5765-5775, ${ }^{71}$ permission conveyed through Copyright Clearance Center,Inc. 
area, uniformly adjustable pore size, high drug loading capacity, high biocompatibility, and easy surface modification. According to whether the mesoporous is ordered, it can be divided into disordered mesoporous silica and ordered mesoporous silica. The current research focuses mainly on the ordered mesoporous silica due to the highly ordered channel structure, regular pore size distribution, and a variety of mesoporous shapes suitable for drug delivery. Kresge et al, who are the scientists of Mobil Company, have reported an ordered mesoporous material called MCM-41 for the first time in 1992. The pore structure of this new type of nanomaterials is an ordered two-dimensional hexagonal arranged with uniform particle size and the pore size can be continuously adjusted in the range of $2-10 \mathrm{~nm} .{ }^{35}$ By controlling the synthesis conditions, various forms of mesoporous silica have been produced continuously. Table 1 Summaries of the types and characteristics of some common mesoporous silica nanomaterials.

\section{Synthesis of Mesoporous Silica Nanomaterials}

In 1968, Werner Stöber and his colleagues first discovered a physicochemical method for the synthesis of spherical monodisperse micron-sized silica particles by adding tetraethyl orthosilicate (TEOS) to ethanol and ammonia water to generate silica particles. ${ }^{43}$ In order to obtain monodisperse and highly ordered silica nanoparticles, researchers have made various improvements to the Stöber method. At present, the most used method for mesoporous silica synthesis is the sol-gel method, which is based on the modified Stöber synthesis method, ${ }^{30}$ which introduces a surfactant (cationic or anionic or nonionic surfactant) as a structure guide agent, and TEOS or silicate as the silicon source. Under alkaline conditions, the surfactant is stirred with the mixed solution of water and alcohol, and then the silicon source is added under stirring to prepare mesoporous silica through the chemical reaction of hydrolysis and condensation of the silicon source in the solution (Figure 2). ${ }^{44}$

Another synthetic method of mesoporous silica is evaporation-induced self-assembly (EISA). In this method, the surfactant is first prepared with a surfactant in an ethanol/ water solvent. During the evaporation of the solvent, the surfactant concentration will gradually increase, resulting in silica/surfactant glue self-assembly of beams, and silica and surfactant will co-assemble into liquid crystal mesophase. ${ }^{44,45}$

\section{Formation Mechanism of Mesoporous Silica}

The specific formation mechanism of mesoporous silica has not been clearly explained. A thorough understanding of the formation mechanism of mesoporous silica can help to prepare specific drug delivery nanoparticles. Kresge et al believed that MCM-41 is synthesized through the liquid crystal template mechanism (Figure 3A). Since the surfactant has dual hydrophilic groups, rod-shaped micelles are formed when the critical micelle concentration (CMC) is reached in the aqueous solution. They are self-assembled and arranged into an orderly "liquid crystal" structure. When

Table I Classification and Characteristics of Common Mesoporous Silica Nanomaterials

\begin{tabular}{|c|c|c|c|c|c|c|c|}
\hline Name & Pore Structure & $\begin{array}{l}\text { Crystal } \\
\text { Structure }\end{array}$ & $\begin{array}{l}\text { Pore Sizel } \\
\mathrm{nm}\end{array}$ & Surfactant & $\begin{array}{l}\text { Silicon } \\
\text { Source }\end{array}$ & $\begin{array}{l}\text { Synthetic } \\
\text { Environment }\end{array}$ & Ref. \\
\hline MCM-4I & $\begin{array}{l}\text { Two-dimensional (straight } \\
\text { channel) }\end{array}$ & Hexagonal & $2 \sim 10$ & CTAB & TEOS & Alkaline & [35] \\
\hline MCM-48 & Three-dimensional (Cross hole) & Cubic & $2 \sim 4$ & $\mathrm{PF} 127$ & TEOS & Alkaline & [36] \\
\hline MCM-50 & $\begin{array}{l}\text { Two-dimensional (straight } \\
\text { channel) }\end{array}$ & Lamellar & $10 \sim 20$ & $\begin{array}{l}\mathrm{C}_{n} \mathrm{H}_{2 n+1} \\
\mathrm{~N}\left(\mathrm{CH}_{3}\right)_{3}\end{array}$ & TEOS & Alkaline & [37] \\
\hline SBA-I & Three-dimensional (Cage hole) & Cubic & $2 \sim 3$ & PAA, CPC & TEOS & Acidic & [38] \\
\hline SBA-15 & $\begin{array}{l}\text { Two-dimensional (straight } \\
\text { channel) }\end{array}$ & Hexagonal & $5 \sim 30$ & $\mathrm{EO}_{20} \mathrm{PO}_{70} \mathrm{EO}_{20}$ & TEOS & Acidic & [39] \\
\hline SBA-16 & Three-dimensional (Cross hole) & Cubic & $5 \sim 30$ & $\begin{array}{l}\mathrm{EO}_{106} \mathrm{PO}_{70} \\
\mathrm{EO}_{106}\end{array}$ & TEOS & Acidic & [40] \\
\hline HMS & Short-range ordered channels & Hexagonal & $2 \sim 10$ & $\mathrm{C}_{\mathrm{n}} \mathrm{H}_{2 n+1} \mathrm{NH}_{2}$ & TEOS & Neutral & [4I] \\
\hline MSU-X & Wormhole & Hexagonal & $2 \sim 15$ & $\mathrm{C}_{n} \mathrm{H}_{2 \mathrm{n}+1}(\mathrm{EO})_{\mathrm{m}}$ & TEOS & Neutral & [42] \\
\hline
\end{tabular}

Abbreviations: CTAB, cetyltrimethylammonium bromide; TEOS, tetraethyl orthosilicate; PAA, polyacrylic acid; CPC, cetylpyridine chloride. 


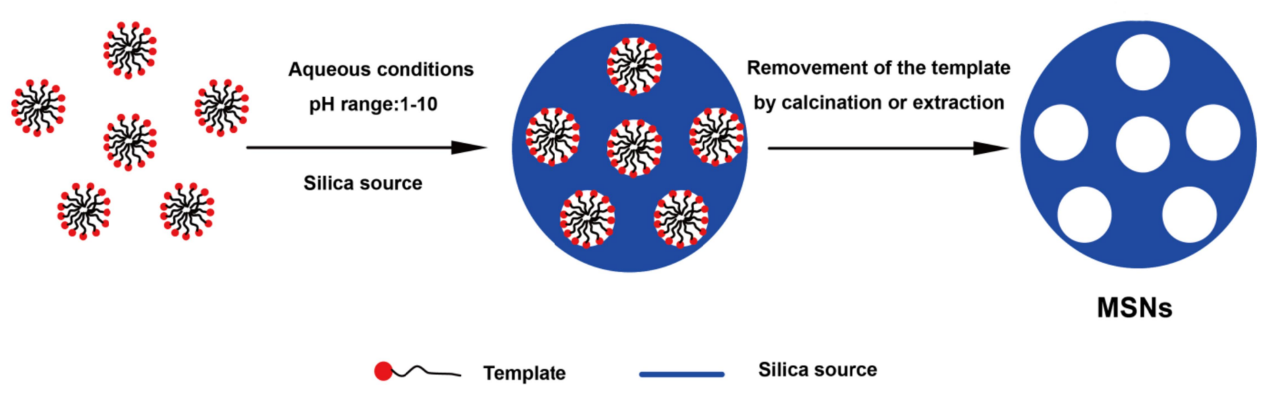

Figure 2 A schematic diagram of the synthesis of MSNs.

Notes: Li Z, Zhang Y, Feng N. Mesoporous silica nanoparticles: synthesis, classification, drug loading, pharmacokinetics, biocompatibility, and application in drug delivery. Expert Opin Drug Deliv. 2019;16(3):219-237, reprinted by permission of the publisher (Taylor \& Francis Ltd, http://www.tandfonline.com). ${ }^{44}$

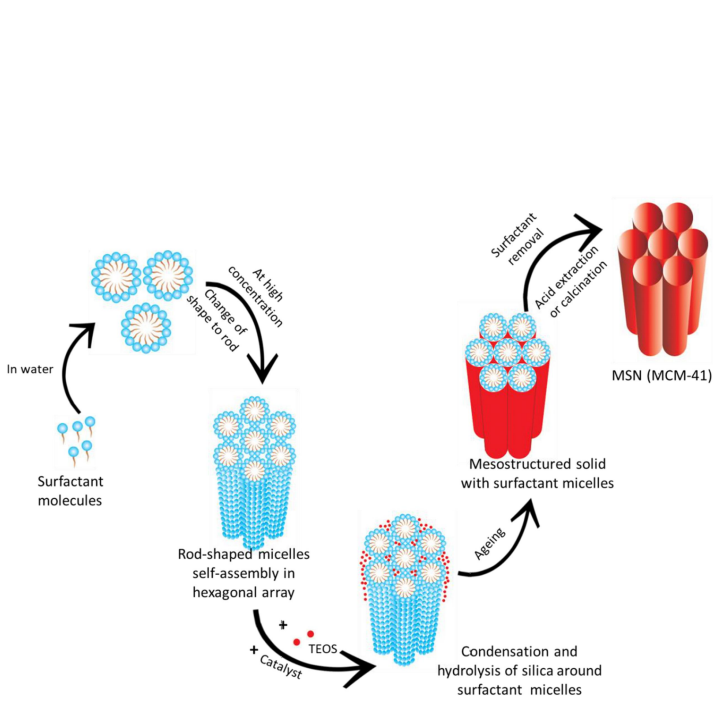

A
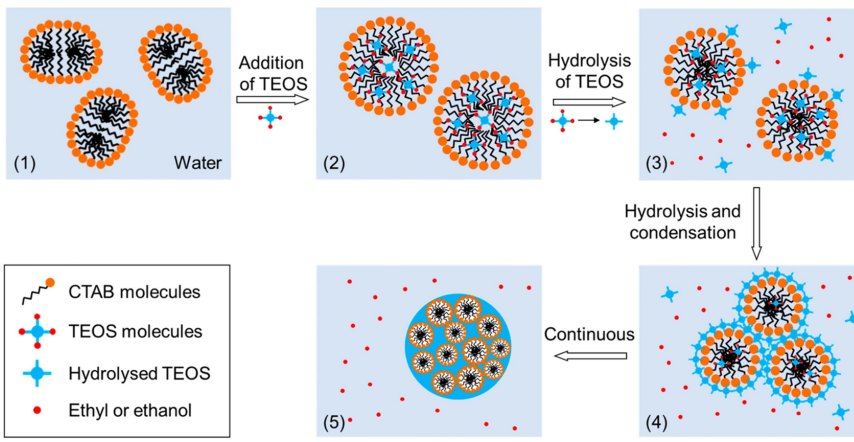

.
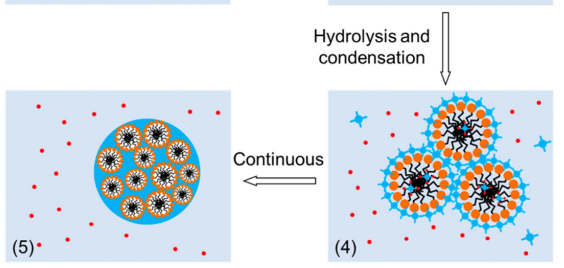

B
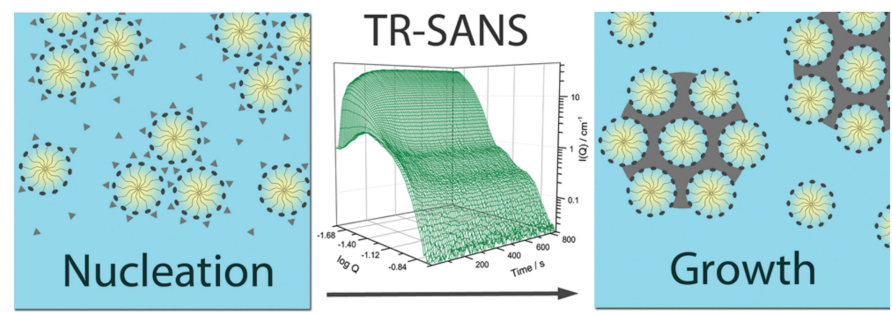

C

Figure 3 Schematic diagrams of the formation mechanism of mesoporous silica. (A) Scheme of the formation mechanism of MCM-4I. (B) SANS method. (C) "expansion and contraction" mechanism.

Notes: (A) Narayan R, Nayak UY, Raichur AM, et al. Mesoporous Silica Nanoparticles: A Comprehensive Review on Synthesis and Recent Advances. Pharmaceutics. 2018;10(3), reprinted by permission of the publisher (Taylor \& Francis Ltd, http://www.tandfonline.com). ${ }^{45}$ (B) Reprinted with permission from Yi Z, Dumee LF, Garvey CJ, et al. A new insight into growth mechanism and kinetics of mesoporous silica nanoparticles by in situ small-angle X-ray scattering. Langmuir. 2015 ; 31 (30): 8478-8487. Copyright (2015) American Chemical Society. ${ }^{46}$ (C) Reprinted with permission from Hollamby MJ, Borisova D, Brown P, et al. Growth of mesoporous silica nanoparticles monitored by time-resolved small-angle neutron scattering. Langmuir. 2012;28(9): 4425-4433. Copyright (20I5) American Chemical Society. ${ }^{47}$

silicon source is added, silicate ions will combine with surfactant ions due to static electricity to attach to the surface of surfactant micelles. The organic substances are then removed after washing, drying, and calcining the product. Finally, the framework-like regularly arranged silicate network is left to form mesoporous silica. ${ }^{35}$

The formation mechanism of mesoporous silica was also studied by time-resolved small-angle neutron scattering (SANS) method (Figure 3B). It was found that during the early hydrolysis of silicon source, tetramethyl orthosilicate (TMOS), silicate ions are adsorbed around the cationic surfactant micelles, and the charge around the surfactant is reduced due to the initial hydrolysis and condensation of the silicon source, resulting in a reduction in the repulsive force between the micelles. Then, the small silica aggregates are formed, and finally, hexagonal ordered mesoporous silica is obtained. ${ }^{45-47}$

In addition, some researchers have proposed another mechanism called "expansion and contraction", which provides new ideas for the formation of mesoporous silica 
(Figure 3C). For the "expansion and contraction" mechanism, cetyltrimethylammonium bromide (CTAB) is commonly used as the structure-directing agent. Firstly, CTAB is dissolved in a buffer solution with a $\mathrm{pH}$ of 7.2, and then TEOS dissolved in the hydrophobic core is introduced, resulting in the increase of the micelles. When the TEOS in the CTAB hydrophobic core is completely consumed, the micelles will shrink and become smaller. As the processes of hydrolysis and condensation occur simultaneously, the micelles continue to shrink until all TEOS are hydrolyzed and a silica shell is formed around the micelles. ${ }^{45,46}$

\section{Surface Modification and Functionalization of Mesoporous Silica}

Since the surface of mesoporous silica contains a large number of hydroxyl groups, it is very easy to agglomerate, which affects their dispersibility and water solubility, resulting in a significant reduction in the application of assembly materials. Therefore, the researchers tried to modify the surface of mesoporous silica to reduce its surface energy and effectively improve its dispersibility and utilization rate. The current modification methods mainly include surface physical modification and surface chemical modification. Surface physical modification mainly utilizes adsorption, wrapping and other physical effects to modify the surface of mesoporous silica by means of ultraviolet rays and plasma. The surface chemical modification is commonly via the interaction between the coupling agent containing organic functional groups (such as $-\mathrm{NH}_{2},-\mathrm{Cl},-\mathrm{SH}$ or $-\mathrm{CN}$, etc.) and mesoporous silica, to realize the surface modification of mesoporous silica by grafting functional groups onto the pore wall of mesoporous silica in a covalent bond manner.

Currently, there are two main methods of surface chemical modification: co-condensation and post-synthesis. The cocondensation method as a one-step preparation method is to add an organic coupling agent and an inorganic source to the solution simultaneously. With the help of a template agent, functional groups are introduced into the pore channels to realize the surface functionalization with the generation of a mesoporous structure. For the post-synthesis method, mesoporous silica is prepared firstly, and then the coupling agent is added and the whole solution is refluxed in an organic solvent. ${ }^{48}$ Compared with the co-condensation method, the post-synthesis method can control the morphology, structure, particle size and pore size of the mesoporous silica more easily, which is more widely used. Mehmood et al synthesized mesoporous silica using a modified sol-gel method and then functionalized its surface with amino group (Figure 4A). ${ }^{49}$ The mesoporous silica nanoparticles loaded with sofosbuvir were surface-modified by a post-synthesis method using 3-aminopropyltriethoxysilane (APTES) and polyvinyl alcohol (PVA) for amino group modification of MSN to realize sustained drug release. The experimental results showed that the amino-decorated MSNs exhibited Fickian diffusion controlled drug release as compared with non-functionalized and PVAgrafted MSNs. He et al synthesized amino-functionalized mesoporous silica nanoparticles $\left(\mathrm{MSN}-\mathrm{NH}_{2}\right)$ by postgrafting and employed doxorubicin hydrochloride (DOX) as a model drug to evaluate their drug loading and release performance. ${ }^{50}$ It showed that as the mass ratio of $\mathrm{MSN}-\mathrm{NH}_{2}$ /DOX decreased or the density of amino groups increased, the DOX loading efficiency increased significantly.

In addition, mesoporous silica can also be surface modified with polymer. Wang et al prepared a series of poly(amidoamine) (PAMAM)-modified MSNPs (MSNPs-G0 MSNPs-G3) by grafting zero to third generation PAMAM dendrimers onto the surface of mesoporous silica nanoparticles by a layer-by-layer grafting method (Figure 4B). ${ }^{51}$ The obtained NPs were used for mucoadhesive drug delivery systems. With the number of PAMAM amino groups increased, the mucoadhesive ability of PAMAM-modified MSNPs was enhanced. After encapsulating DOX in the mesopores of MSNPs-G2, Dox@MSNPs-G2 sustained DOX release triggered by acidic $\mathrm{pH}$.

Although mesoporous silica has a high drug loading rate and can control the release rate of drug, the liver, kidney and other organs will non-specifically take the drug and cause systemic toxicity before the released drug reaches the target site. Therefore, researchers employ activatable functionalization concept to address this issue and mesoporous silica with the ability of stimuli-responsive drug release such as $\mathrm{pH}$-responsive, ${ }^{52-55}$ temperature-responsive, ${ }^{56}$ redox-responsive, ${ }^{57-60}$ enzymeresponsive, ${ }^{61,62}$ magnetic-responsive, ${ }^{63-65}$ and jointstimulus-responsive ${ }^{66,67}$ have been well developed. However, it should be mentioned that up to now, most of them were all designed for the diagnosis and treatment of tumor.

\section{Application of Mesoporous Silica Nanomaterial-Based Drug Delivery System in Atherosclerosis}

Since Vallet-Regi et al reported the loading of ibuprofen into MCM-41 type MSNs as drug delivery system in 2001 
A

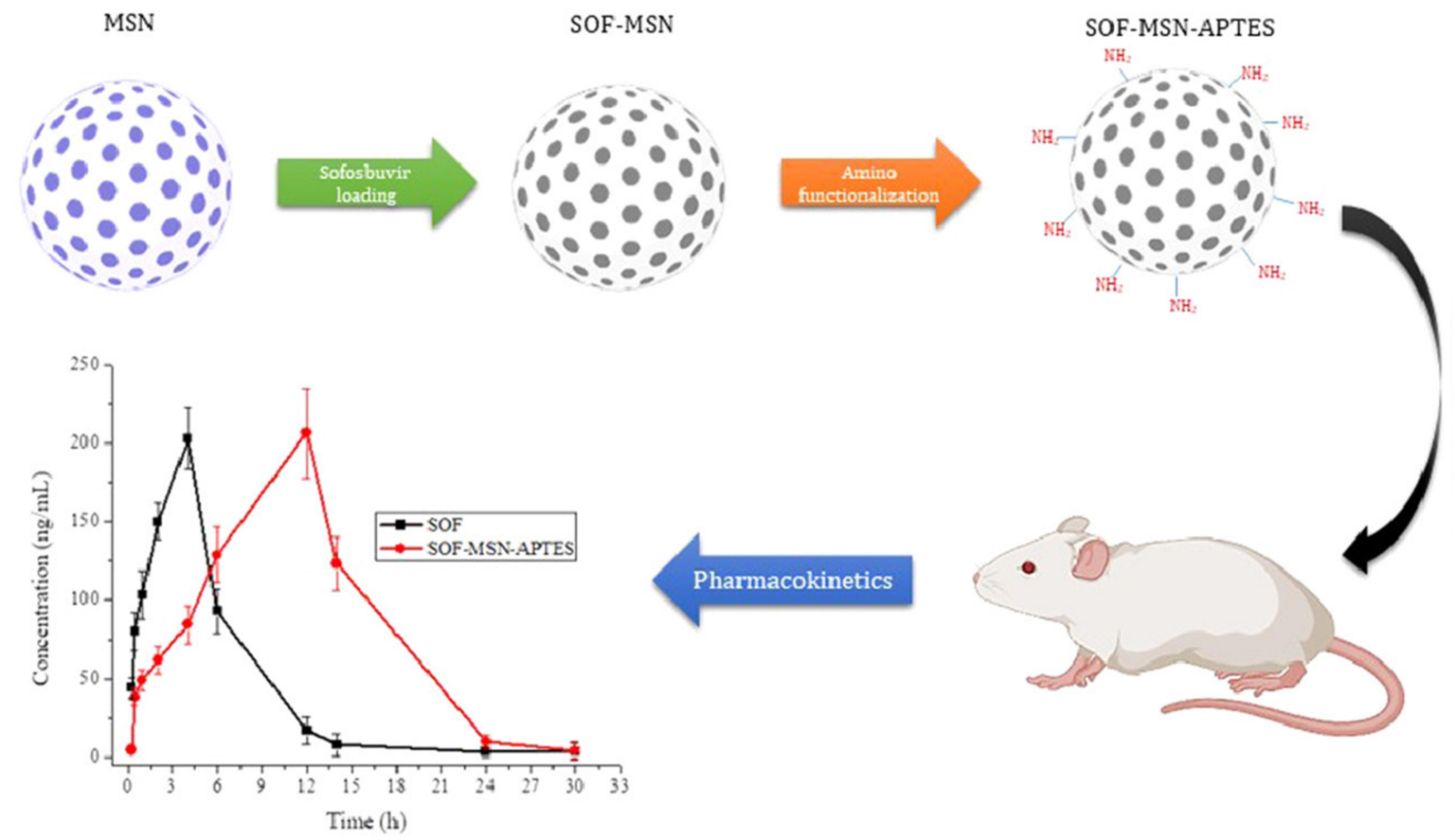

B

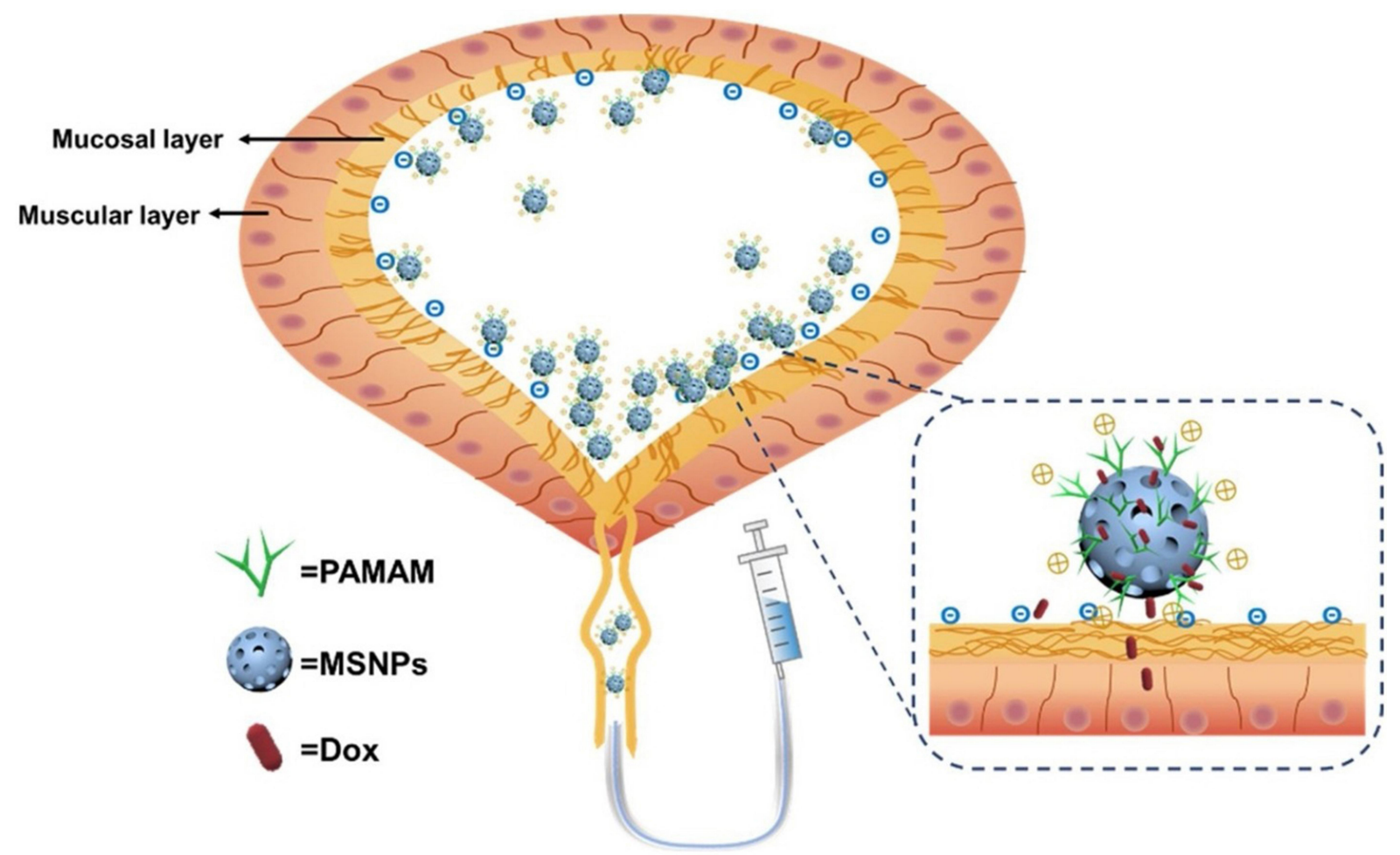

Figure 4 A schematic diagram of surface modification of mesoporous silica. (A) amino functionalization. (B) polymer modification.

Notes: (A) Reprinted from Eur J Pharm Sci, I43, Mehmood Y, Khan IU, Shahzad Y, et al. Amino-decorated mesoporous silica nanoparticles for controlled sofosbuvir delivery, 105184, copyright (2020), with permission from Elsevier. ${ }^{49}$ (B) Reprinted from Colloids Surf B Biointerfaces, I89, Wang B, Zhang K, Wang J, et al. Poly(amidoamine)-modified mesoporous silica nanoparticles as a mucoadhesive drug delivery system for potential bladder cancer therapy, 11 0832, copyright (2020, with permission from Elsevier). ${ }^{51}$

for the first time, mesoporous silica has been widely used as drug delivery nanocarriers in tumors. ${ }^{68}$ Mesoporous silica possesses a series of excellent properties for their use as drug delivery carrier, such as highly ordered pores, high specific surface area and large pore volume. Particularly, its pore size is uniformly distributed and 
controllable and can be adjusted in a wide range, favoring the loading of different substances on demand. In addition, the shape of mesopores and the composition and properties of the pore walls can also be adjusted, contributing to the controllable release of drug. These unique physical and chemical properties make mesoporous silica a suitable carrier for drug delivery. The high drug-carrying capacity and co-carrying capacity of mesoporous silica also make it possible to overcome multiple drug-resistant tumors. ${ }^{69}$ In addition, the retention effect and high permeability effect (EPR effect) of the solid tumor allow nanoparticles to be passively targeted to the tumor site, which further enhances the killing effect of nano-medicine on tumors. These outstanding properties of mesoporous silica for drug delivery in tumor show their promising potentials for AS, which is a chronic inflammatory vascular disease with the lipid-rich plaques accumulated on the arterial wall. In recent years, researchers have designed mesoporous silicabased diagnosis and therapy systems for AS. Table 2 summarizes the applications of mesoporous silica in AS.
Macrophages play a vital role in the formation of AS. ${ }^{76}$ Chemotactic factors such as monocyte chemoattractant protein 1 (MCP-1) and adhesion molecules can chemo attract inflammatory monocytes in the blood to migrate to the artery intima, and the monocytes in the inner layer are activated in response to macrophage colony stimulating factor and further differentiate into macrophages. ${ }^{77,78}$ Macrophages actively internalize and modify lipids and transform into foam cells to accelerate the formation of AS. Therefore, tracking macrophages is a promising method for the diagnosis of AS. Jeong et al designed the aza-dibenzocyclooctyne polymerized PEGylated mesoporous silica nanoparticles (DBCO-MSNs) with biological orthogonal F-18 labeling to track macrophage cells by Positron Emission Computed Tomography (PET) (Figure 5A). ${ }^{74}$ The experimental results showed that ${ }^{18} \mathrm{~F}$-DBCOMSNs labeled macrophage cells (RAW264.7) could home and accumulate at atherosclerotic plaque and could be monitored by PET images. Such DBCO-functionalized MSNs can provide a new strategy for the diagnosis of

Table 2 Summary of Application of Mesoporous Silica in Atherosclerosis

\begin{tabular}{|c|c|c|c|c|c|}
\hline Nanomaterials & Surface Modification & Drug & Targeting Mechanism & Functions & Ref. \\
\hline $\begin{array}{l}\text { PPI-IO@MS- } \\
\text { IR820 (PIMI) }\end{array}$ & PPI & $\begin{array}{l}\text { IR820 (near- } \\
\text { infrared } \\
\text { fluorescence } \\
\text { dye) }\end{array}$ & $\begin{array}{l}\text { Targeting foamy macrophage } \\
\text { through SR-Al(an overexpressed } \\
\text { surface receptor) }\end{array}$ & Dual MR/NIRF imaging & [70] \\
\hline MJAMS/PTX/aV & $\begin{array}{l}\text { I. sputtere Pt on one-side of AMS } \\
\text { 2. modify anti-VCAM-I antibody } 3 . \\
\text { platelet membrane coated }\end{array}$ & PTX & $\begin{array}{l}\text { Nanomotor can penetrate deeply } \\
\text { into the plaque under the } \\
\text { irradiation of near-infrared (NIR) } \\
\text { light }\end{array}$ & $\begin{array}{l}\text { I. short-term } \\
\text { photothermal } \\
\text { elimination of } \\
\text { inflammatory } \\
\text { macrophages } \\
\text { 2. long-term anti- } \\
\text { proliferation effect of } \\
\text { the drug }\end{array}$ & [7I] \\
\hline $\begin{array}{l}\text { FITC-VHP- } \\
\mathrm{Fe}_{3} \mathrm{O}_{4} @ \mathrm{SiO}_{2}\end{array}$ & The peptide VHPKQHR & $\mathrm{N} / \mathrm{A}$ & VCAM-I targeting & $\begin{array}{l}\text { Fluorescence/magnetic } \\
\text { resonance imaging }\end{array}$ & [72] \\
\hline SiN@QC-PLGA & $\mathrm{N} / \mathrm{A}$ & Quercetin & N/A & $\begin{array}{l}\text { Control the medication } \\
\text { discharge conduct from } \\
\text { the nanobiocarriers }\end{array}$ & [73] \\
\hline $\begin{array}{l}{ }^{18} \mathrm{~F}-\mathrm{DBCOT}- \\
\mathrm{MSNs}\end{array}$ & $\begin{array}{l}\text { DBCO-functionalized (aza- } \\
\text { dibenzocyclooctyne-tethered } \\
\text { PEGylated) }\end{array}$ & $N / A$ & Macrophage cell-tracking & PET imaging & [74] \\
\hline CD68-Fe-HSNs & Anti-CD68 antibody & $\mathrm{N} / \mathrm{A}$ & $\begin{array}{l}\text { Targeting macrophage through } \\
\text { CD68 receptor }\end{array}$ & $\begin{array}{l}\text { Dual-modal US/MRI } \\
\text { imaging }\end{array}$ & [75] \\
\hline
\end{tabular}

Abbreviations: PPI, an overexpressed surface receptor (SR-Al) driven foamy macrophage-targeted peptide; IO, iron oxide; MS, mesoporous silica; MR, magnetic resonance; NIRF, near-infrared fluorescence; Pt, platinum; VCAM-I, vascular cell adhesion molecule-I; PTX, paclitaxel; VHPKQHR, Val-His-Pro-Lys-Gln-HisArg; FITC, fluorescein isothiocyanate isomer; PLGA, poly(lactic-co-glycolic acid); PET, positron emission tomography; US, ultrasound. 
AS with PET imaging. Ji et al fabricated anti-CD68 receptor-targeted Fe-doped hollow silica nanoparticles (CD68Fe-HSNs) as a dual-modal US/MRI contrast agent to identify macrophages of aorta ventralis atherosclerotic plaques in ApoE-/- mice (Figure 5B).$^{75}$ In addition, the CD68-Fe-HSNs were biodegradable, even though they were inorganic mesoporous nanosystems, indicating their potentials for drug delivery and AS theranostic. Since AS is an inflammatory disease, high expression of inflammatory molecules can also be used as targeting molecules for AS tracking. $\mathrm{Xu}$ et al designed mesoporous silica nanoparticles that could target vascular cell adhesion molecule 1 (VCAM-1) expressed by endothelial cells. ${ }^{72}$ VHPKQHR peptide-modified magnetic mesoporous nanoparticles (FITC-VHP- $\mathrm{Fe}_{3} \mathrm{O}_{4} @ \mathrm{SiO}_{2}$ ) were constructed by incorporating fluorescein isothiocyanate (FITC) into $\mathrm{Fe}_{3} \mathrm{O}_{4} @ \mathrm{SiO}_{2}$ and modifying VHPKQHR (Val-His-Pro-Lys-Gln-His$\mathrm{Arg}$ ) peptide on their surface. In vitro fluorescence imaging and in vivo magnetic resonance imaging showed that FITC-VHP- $\mathrm{Fe}_{3} \mathrm{O}_{4} @ \mathrm{SiO}_{2}$ could accurately target atherosclerotic plaque sites. In this paper, although the authors did not apply for drug delivery, they displayed the possibility of future accurate delivery of drugs by MRI guided with FITC-VHP-Fe $\mathrm{O}_{4} @ \mathrm{SiO}_{2}$ for AS.

In the treatment of AS, Huang et al synthesized a paclitaxel drug-loaded platelet membrane bionic Janus mesoporous silica porous nanomotors (JAMS) that were obtained by asymmetric modification of platinum (Pt) nanoparticles. ${ }^{71}$ After the NIR irradiation, the nanomotors can not only penetrate the plaque and enhance the drug retention efficiency but also realize short-term photothermal elimination of inflammatory macrophages and longterm anti-proliferation effect of the drug (Figure 5C). The introduction of nanomotor, platelet membrane coating and the combination of photothermal and drug therapy provided a new avenue for the treatment of AS with high efficiency.

Wang et al prepared a new polymer superparamagnetic nano-silica (SiN)@quercetin (QC)-coated poly(lactic-coglycolic acid) (PLGA) nanocomposite (SiN@QC-PLGA) by lyophilization to control the medication discharge conduct. ${ }^{73}$ The results indicated that the SiN@QC-PLGA nanocomposite essentially improved the actual similarity of the local myocardium, favoring the cell enlistment, attachment, expansion and articulation of heart proteins. The structure and manufacture of this nanocomplex can control the medication discharge conduct from the nanocarriers and thusly diminish the required incessant infusion, which might have the potential to be used for the anticipation of AS and other relative cardiovascular diseases.

However, compared with mesoporous silica-based drug delivery systems for the theranostic applications in tumor, their uses for the diagnosis and treatment of AS are scarce up to now, which might come from the adverse effect of mesoporous silica on the development of AS. We will discuss the existing challenges in the following paragraph in detail.

\section{Challenges of Mesoporous Silica Nanomaterials in Atherosclerosis}

Although the above literatures showed the usage of mesoporous silica nanomaterials for the diagnosis and therapy of AS, it should be mentioned that mesoporous silica nanomaterials have displayed an adverse effect on the development of AS in some reports in recent years. For example, Liu et al found that silica nanoparticles could induce endothelial cell dysfunction through oxidative stress through the JNK/p53 and NF-kB pathways, ${ }^{79}$ and could also enhance the proinflammatory and procoagulant responses significantly to trigger or exacerbate AS through CD40-CD40L-mediated monocyte-endothelial cell interactions. ${ }^{80}$ Guo et al found that silica nanoparticles could induce oxidative stress, inflammation and interfere with the nitric oxide (NO)/nitric oxide synthase (NOS) system, and ultimately led to endothelial dysfunction by activating the MAPK/Nrf2 pathway and nuclear factor- $\mathrm{KB}$ signal transduction. ${ }^{81}$ Petrick et al incubated the mouse cell line macrophages J774.1 with silica nanoparticles, and then performed cytotoxicity tests, oxidative stress, triglyceride (TG) and cholesterol metabolism analysis to study the atherogenic effect of silica in vitro. ${ }^{82}$ The experimental results showed that compared with J774A.1 cultured murine macrophage cells without the treatment of $\mathrm{SiO}_{2}$, a significant dose-dependent increase in oxidative stress (up to 164\%), in cytotoxicity (up to $390 \%$ measured by lactate dehydrogenase (LDH) release), and in TG content (up to $63 \%$ ) was observed in $\mathrm{SiO}_{2}$ exposed macrophages. Therefore, silica nanoparticles exhibited pro-atherogenic effects on macrophages through the observation of cytotoxicity, increased oxidative stress and TG accumulation. Guo et al studied their effect on the metabolism of macrophage-derived lipids, foam cell formation and macrophage apoptosis when silica nanoparticles (SiNPs) and oxLDL were exposed together to Raw264.7 cells (Figure 6). ${ }^{83}$ They found that SiNPs could promote the accumulation 


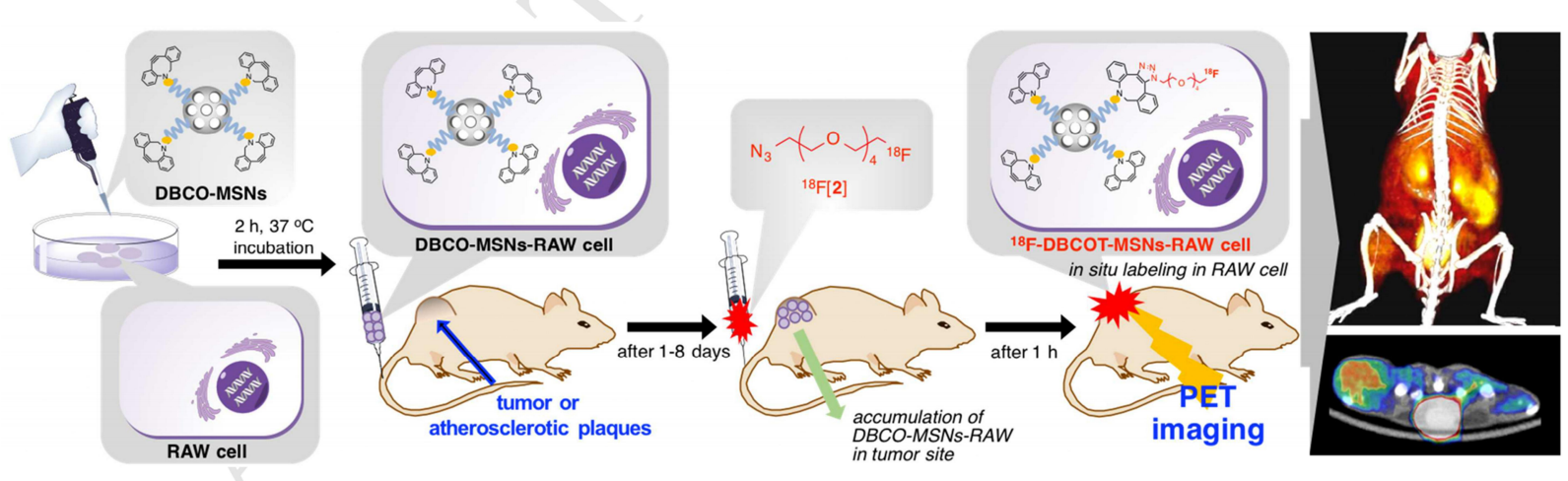

A
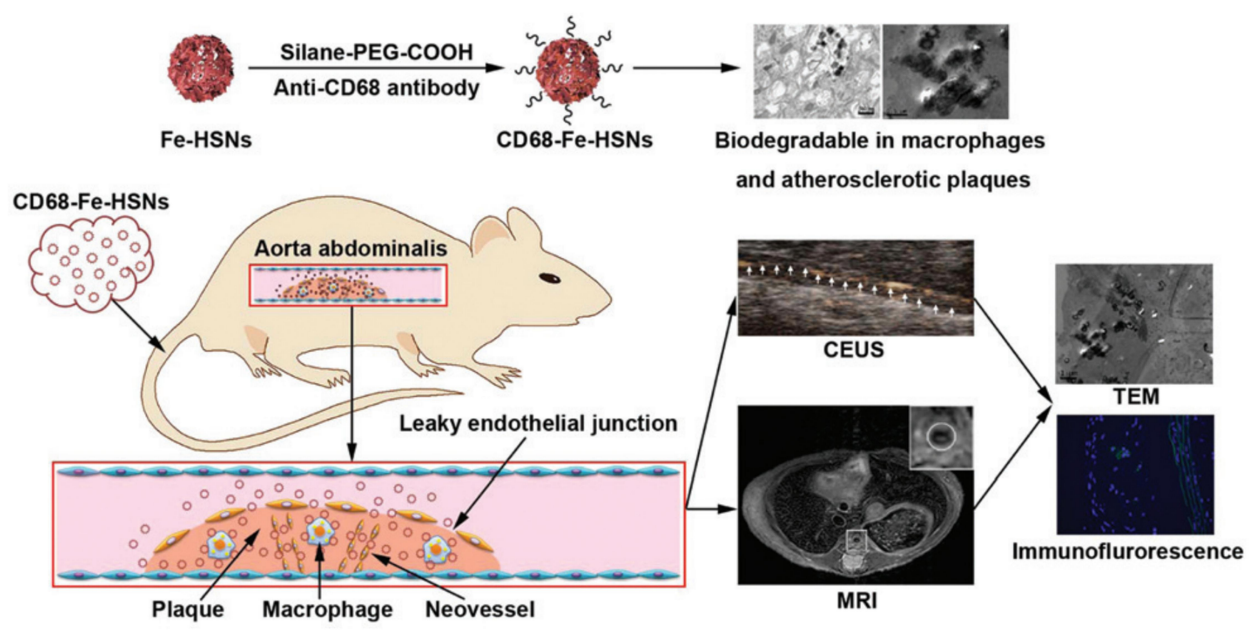

B

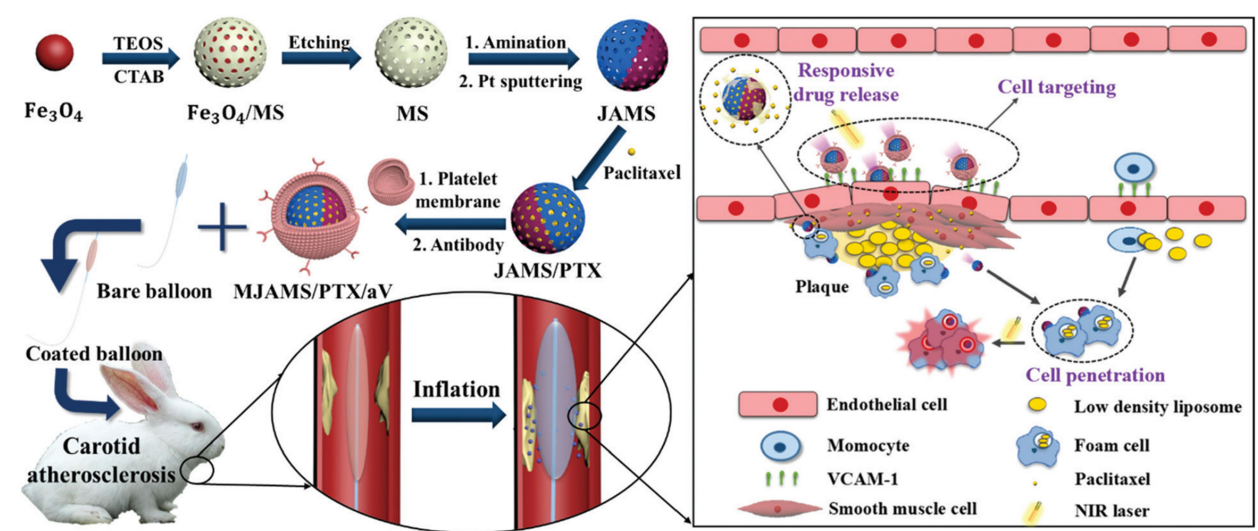

C

Figure 5 Applications of mesoporous silica in the diagnosis and treatment of AS. (A) A schematic diagram of an effective macrophage tracking protocol based on an in vivo bioorthogonal F-18 labeling reaction using the PET system. (B) Schematic illustration of identifying macrophage enrichment in atherosclerotic plaques by dual-modal US imaging and MRI based on biodegradable CD68-Fe-HSN. (C) Schematic illustration of the synthesis process of MJAMS/PTX/aV and the mechanism of treatment of AS using the MJAMS/PTX/aV coated balloon.

Notes: Reprinted from Biomaterials, 199, Jeong HJ, Yoo RJ, Kim JK, et al. Macrophage cell tracking PET imaging using mesoporous silica nanoparticles via in vivo bioorthogonal F-18 labeling. 32-39, copyright (2019), with permission from Elsevier. ${ }^{74}$ Reproduced from Ji R, Li X, Zhou C, et al. Identifying macrophage enrichment in atherosclerotic plaques by targeting dual-modal US imaging/MRI based on biodegradable Fe-doped hollow silica nanospheres conjugated with anti-CD68 antibody. Nanoscale. 2018; 10(43):20246-20255. ${ }^{75}$ Huang Y, Li T, Gao W, et al. Platelet-derived nanomotor coated balloon for atherosclerosis combination therapy. J Mater Chem B Mater Biol Med. 2020;8(26):5765-5775. ${ }^{11}$ 


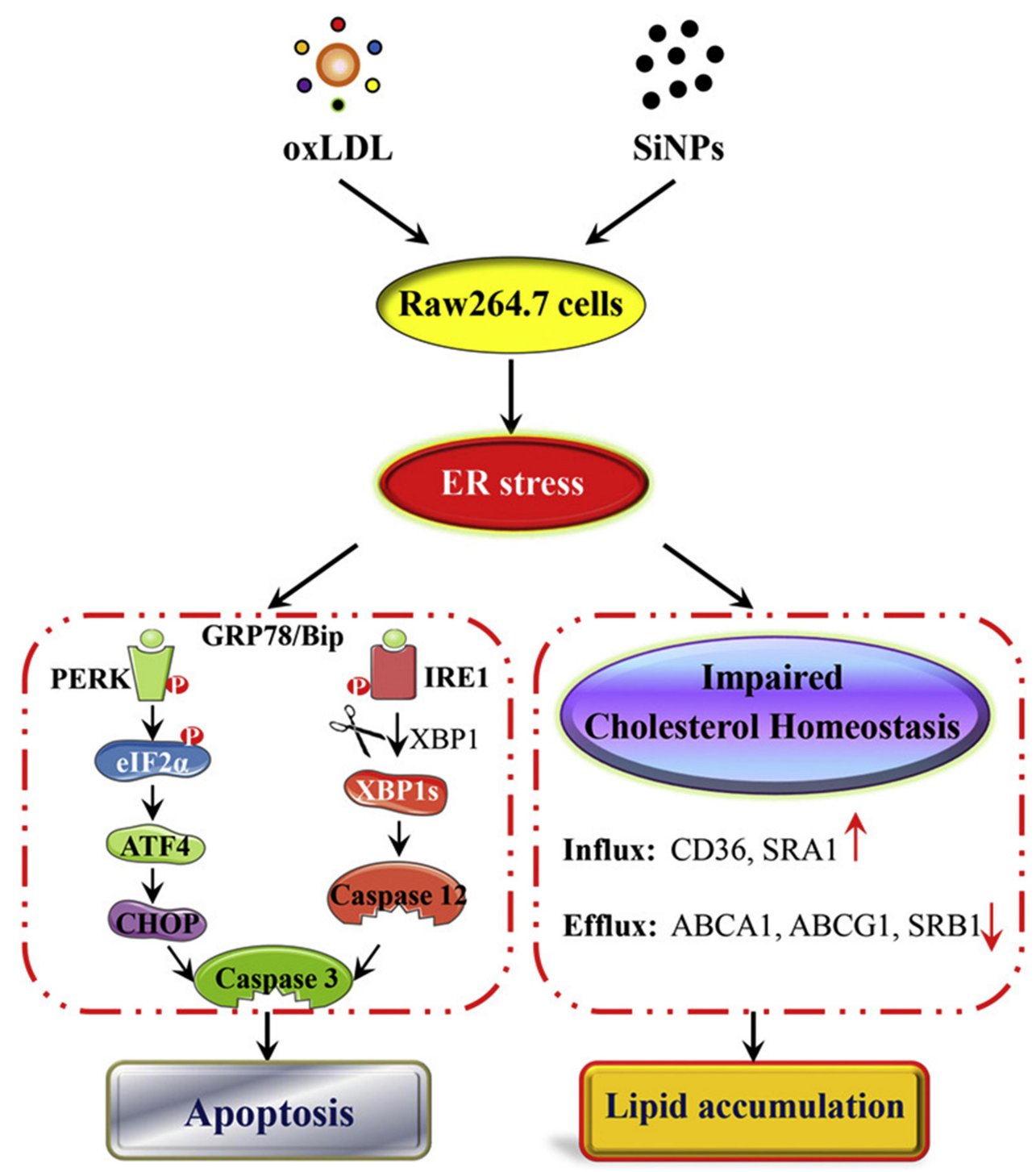

Figure 6 The induction of foam cell along with the disturbance on cholesterol influx/efflux balance, and promotion of apoptosis via ER stress PERK/elF2 $\alpha / A T F 4$ and IREI $\alpha /$ XBPI signaling cascade by SiNPs and oxLDL coexposure in a macrophage model.

Notes: Reprinted from Sci Total Environ, 63I-632, Guo C, Ma R, Liu X, et al. Silica nanoparticles promote oxLDL-induced macrophage lipid accumulation and apoptosis via endoplasmic reticulum stress signaling. 570-579, copyright (2018), with permission from Elsevier. ${ }^{83}$

of lipids in macrophages by promoting the inflow of cholesterol and inhibiting the outflow of cholesterol under the stimulation of oxLDL. In addition, SiNPs also promoted oxLDL-induced foam cell formation and macrophage apoptosis. All of the above researches show that it is still a challenge to develop silica nanoparticle-based theranostic system for AS at present although some related applications have been reported. More attention on the mechanism and the control method of such influence should be paid to broaden the theranostic applications of mesoporous silica nanomaterials for AS.

With the continuous development of nano-engineering technology, cell membrane-derived biomimetic nanoparticles have attracted extensive attention from researchers due to their excellent biocompatibility. Cell membrane-derived biomimetic nanoparticles can be recognized as "self" in vivo, so they can evade the immune system more effectively, prolong blood circulation, and improve their ability to target lesions through the biological properties of the cell membrane surface. ${ }^{84}$ Xuan et al presented magnetic mesoporous silica nanoparticles cloaked with red blood cell membrane (RBC@MMSNs) which integrates with long circulation, photosensitizer delivery and magnetic targeting feature for cancer therapy. ${ }^{85}$ Since derived from the natural features of source cell, the RBC@MMSN-HB expresses remarkable properties of stability, biocompatibility, and prolonged 
circulation, reduced retention in reticuloendothelial system, and improved tumorous accumulation. They also fabricated macrophage cell membrane (MPCM)-camouflaged mesoporous silica nanocapsules (MSNCs) through a top-down assembly as a biomimetic drug delivery platform again ${ }^{86}$ Compared with RBC membrane-coated nanoparticles, the MPCMcamouflaged MSNCs not only exhibited good in vivo stability, reduced retention in RES organs, prolonged blood-circulating time, and improved tumoritropic accumulation, but also provided active targeting ability by recognizing tumor endothelium through the existing surface proteins on the MPCMs. Benefitting from the properties of cell membrane, cell membrane-coated mesoporous silica biomimetic nanoparticles might weaken their negative effect for AS development.

Recently, researchers have applied the strategy of cell membrane biomimetic nanoparticles to atherosclerosis. Wang et al fabricated macrophage membrane biomimetic nanoparticles (MM/RAPNPs) through a macrophage membrane coating on the surface of rapamycin-loaded poly (lactic-co-glycolic acid) copolymer (PLGA) nanoparticles based on macrophage "homing" to atherosclerotic lesions. ${ }^{88}$ The experiments demonstrate that MM/RAPNPs showed favorable sustained drug release kinetics, effectively inhibited macrophage phagocytosis and targeted activated endothelial cells in vivo. In vivo, MM/RAPNPs can effectively target and accumulate in atherosclerotic lesions and are significantly delayed the progression of AS after treatment for one month. Song et al explored platelet membrane-coated PLGA nanoparticles (PNP) as atherosclerotic plaque-targeting drug delivery system through mimicking platelets' inherent adhesion to atherosclerosis plaques. ${ }^{89}$ It showed that RAP-PNPs could effectively target atherosclerotic plaques, delay the progression of atherosclerosis and stabilize atherosclerotic plaques.

These studies have confirmed the advantages of cell membrane-derived biomimetic nanoparticles in tumor treatment and atherosclerosis management. Although the nano-core in these studies is not mesoporous silica nanoparticle, we hope this strategy can also be used for mesoporous silica to meet its challenges in AS. The surface coating might weaken the influence of mesoporous silica on the development of AS. In addition, it is possible to design mesoporous silica nanoparticles that have a lower degree of cross-linking and are easily biodegradable in the body to overcome their limitations for the diagnosis and therapy of AS. We expect that these novel designs can provide new strategies for the safe use of mesoporous silica in AS.

\section{Summary}

Mesoporous silica nanomaterials have become the most ideal nanocarriers for the fabrication of drug delivery system due to their high specific surface area, controlled pore volume, high drug loading capacity, and high biocompatibility. In addition, the surface chemical modification of mesoporous silica can be performed to improve its dispersibility and utilization rate. Researchers have designed various functional mesoporous silica-based drug delivery systems to improve their targeting capabilities and control the rate of drug release. Although mesoporous silica-based drug delivery systems have been widely used in tumors, the toxicity and biocompatibility of mesoporous silica to cardiovascular diseases are still worthy of comprehensive and indepth study before their wide applications in AS. Currently, cell membrane biomimetic nanoparticles have received extensive attention. Cell membrane biomimetic nanoparticles can not only evade the immune system's clearance, but also improve the targeting specificity of nanoparticles and reduce their toxic side effects due to they retain the biological properties of the original cell membrane. This may be an effective strategy for the design of mesoporous silica-based drug delivery system for AS. Furthermore, biodegradable mesoporous silica nanomaterials might be another alternative choice to avoid such side effect to develop mesoporous silica-based drug delivery system for AS. It is believed that with the unremitting efforts of researchers, mesoporous silica-based drug delivery systems will have great development prospects in the diagnosis and treatment of cardiovascular diseases such as AS, and will provide more ideas for accurate diagnosis and effective treatment of AS.

\section{Acknowledgments}

This work was supported by the Natural Science Foundation of Jiangsu Province for the Excellent Young Scholars (BK20170054), Qing Lan Project, the Peak of Six Talents of Jiangsu Province (WSN-112), Jiangsu Provincial Medical Youth Talent (QNRC2016776), Six one project of Jiangsu Province (LGY2018083) and Graduate Student Training Innovation Engineering Practice Plan of Jiangsu Province (SJCX18_0708).

\section{Disclosure}

The authors report no conflicts of interest in this work. 


\section{References}

1. Roth GA, Johnson C, Abajobir A, et al. Global, regional, and national burden of cardiovascular diseases for 10 causes, 1990 to 2015. $\mathrm{J} \mathrm{Am}$ Coll Cardiol. 2017;70(1):1-25. doi:10.1016/j.jacc.2017.04.052

2. Peng R, Ji H, Jin L, et al. Macrophage-based therapies for atherosclerosis management. J Immunol Res. 2020;2020:8131754. doi:10.1155/2020/8131754

3. Petersen LK, York AW, Lewis DR, et al. Amphiphilic nanoparticles repress macrophage atherogenesis: novel core/shell designs for scavenger receptor targeting and down-regulation. Mol Pharm. 2014;11 (8):2815-2824. doi:10.1021/mp500188g

4. Wang Y, Zhang K, Qin X, et al. Biomimetic nanotherapies: red blood cell based core-shell structured nanocomplexes for atherosclerosis management. Adv Sci (Weinh). 2019;6(12):1900172. doi:10.1002/ advs.201900172

5. Hu T, Yang J, Cui K, et al. Controlled slow-release drug-eluting stents for the prevention of coronary restenosis: recent progress and future prospects. ACS Appl Mater Interfaces. 2015;7 (22):11695-11712. doi:10.1021/acsami.5b01993

6. Khan R, Spagnoli V, Tardif JC, et al. Novel anti-inflammatory therapies for the treatment of atherosclerosis. Atherosclerosis. 2015;240 (2):497-509. doi:10.1016/j.atherosclerosis.2015.04.783

7. Lan H, Wang Y, Yin T, et al. Progress and prospects of endothelial progenitor cell therapy in coronary stent implantation. $J$ Biomed Mater Res B Appl Biomater. 2016;104(6):1237-1247. doi:10.1002/ jbm.b.33398

8. Shi J, Votruba AR, Farokhzad OC, et al. Nanotechnology in drug delivery and tissue engineering: from discovery to applications. Nano Lett. 2010;10(9):3223-3230. doi:10.1021/nl102184c

9. Shimizu K, Takeuchi Y, Otsuka K, et al. Development of tissue factor-targeted liposomes for effective drug delivery to stroma-rich tumors. $J$ Control Release. 2020;323:519-529. doi:10.1016/j. jconrel.2020.04.043

10. Huang M, Pu Y, Peng Y, et al. Biotin and glucose dual-targeting, ligand-modified liposomes promote breast tumor-specific drug delivery. Bioorg Med Chem Lett. 2020;30(12):127151. doi:10.1016/ j.bmcl.2020.127151

11. Kumar B, Pandey M, Pottoo FH, et al. Liposomes: novel drug delivery approach for targeting Parkinson's disease. Curr Pharm Des. 2020;26(37):4721-4737. doi:10.2174/1381612826666200128 145124

12. Zappavigna S, Abate M, Cossu AM, et al. Urotensin-II-targeted liposomes as a new drug delivery system towards prostate and colon cancer cells. J Oncol. 2019;2019:9293560. doi:10.1155/2019/ 9293560

13. Hu J, Zhuang W, Ma B, et al. Redox-responsive biomimetic polymeric micelle for simultaneous anticancer drug delivery and aggregation-induced emission active imaging. Bioconjug Chem. 2018;29(6):1897-1910. doi:10.1021/acs.bioconjchem.8b00119

14. Sun C, Liang Y, Hao N, et al. A ROS-responsive polymeric micelle with a $\pi$-conjugated thioketal moiety for enhanced drug loading and efficient drug delivery. Org Biomol Chem. 2017;15(43):9176-9185. doi:10.1039/c7ob01975k

15. Triolo D, Craparo EF, Porsio B, et al. Polymeric drug delivery micelle-like nanocarriers for pulmonary administration of beclomethasone dipropionate. Colloids Surf $B$ Biointerfaces. 2017;151:206-214. doi:10.1016/j.colsurfb.2016.11.025

16. Xia H, Zhao Y, Tong R. Ultrasound-mediated polymeric micelle drug delivery. Adv Exp Med Biol. 2016;880:365-384. doi:10.1007/9783-319-22536-4_20

17. Sulaiman GM, Waheeb HM, Jabir MS, et al. Hesperidin loaded on gold nanoparticles as a drug delivery system for a successful biocompatible, anti-cancer, anti-inflammatory and phagocytosis inducer model. Sci Rep. 2020;10(1):9362. doi:10.1038/s41598-020-66419-6
18. Yücel $\mathrm{O}$, Şengelen A, Emik $\mathrm{S}$, et al. Folic acid-modified methotrexate-conjugated gold nanoparticles as nano-sized trojans for drug delivery to folate receptor-positive cancer cells. Nanotechnology. 2020;31(35):355101. doi:10.1088/1361-6528/ ab9395

19. Mahalunkar S, Yadav AS, Gorain M, et al. Functional design of $\mathrm{pH}$-responsive folate-targeted polymer-coated gold nanoparticles for drug delivery and in vivo therapy in breast cancer. Int J Nanomedicine. 2019;14:8285-8302. doi:10.2147/IJN.S215142

20. Hu Y, Niemeyer CM. Designer DNA-silica/carbon nanotube nanocomposites for traceable and targeted drug delivery. $J$ Mater Chem B Mater Biol Med. 2020;8(11):2250-2255. doi:10.1039/c9tb02861g

21. Moradnia H, Raissi H, Shahabi M. The performance of the single-walled carbon nanotube covalently modified with polyethylene glycol to delivery of Gemcitabine anticancer drug in the aqueous environment. $J$ Biomol Struct Dyn. 2020;1-8. doi:10.1080/ 07391102.2020 .1719204

22. Maleki R, Afrouzi HH, Hosseini M, et al. Molecular dynamics simulation of Doxorubicin loading with $\mathrm{N}$-isopropyl acrylamide carbon nanotube in a drug delivery system. Comput Methods Programs Biomed. 2020;184:105303. doi:10.1016/j.cmpb.2019.105303

23. Rakhshaei R, Namazi H, Hamishehkar H, et al. Graphene quantum dot cross-linked carboxymethyl cellulose nanocomposite hydrogel for $\mathrm{pH}$-sensitive oral anticancer drug delivery with potential bioimaging properties. Int J Biol Macromol. 2020;150:1121-1129. doi:10.1016/j. ijbiomac.2019.10.118

24. Gui W, Zhang J, Chen X, et al. N-Doped graphene quantum dot@mesoporous silica nanoparticles modified with hyaluronic acid for fluorescent imaging of tumor cells and drug delivery. Mikrochim Acta. 2017;185(1):66. doi:10.1007/s00604-017-2598-0

25. Javanbakht S, Namazi H. Doxorubicin loaded carboxymethyl cellulose/graphene quantum dot nanocomposite hydrogel films as a potential anticancer drug delivery system. Mater Sci Eng C Mater Biol Appl. 2018;87:50-59. doi:10.1016/j. msec.2018.02.010

26. Ayyanaar S, Balachandran C, Bhaskar RC, et al. ROS-responsive chitosan coated magnetic iron oxide nanoparticles as potential vehicles for targeted drug delivery in cancer therapy. Int J Nanomedicine. 2020;15:3333-3346. doi:10.2147/IJN.S249240

27. Nguyen MP, Thuy VTT, Kim D. Integration of iron oxide nanoparticles and polyaspartamide biopolymer for MRI image contrast enhancement and an efficient drug-delivery system in cancer therapy. Nanotechnology. 2020;31(33):335712. doi:10.1088/13616528/ab8f49

28. Alyassin Y, Sayed EG, Mehta P, et al. Application of mesoporous silica nanoparticles as drug delivery carriers for chemotherapeutic agents. Drug Discov Today. 2020;25(8):1513-1520. doi:10.1016/j. drudis.2020.06.006

29. AbouAitah K, Hassan HA, Swiderska-Sroda A, et al. Targeted nano-drug delivery of colchicine against colon cancer cells by means of mesoporous silica nanoparticles. Cancers (Basel). 2020;12 (1):144. doi:10.3390/cancers 12010144

30. Watermann A, Brieger J. Mesoporous silica nanoparticles as drug delivery vehicles in cancer. Nanomaterials (Basel). 2017;7(7). doi:10.3390/nano7070189

31. Zhou Y, Quan G, Wu Q, et al. Mesoporous silica nanoparticles for drug and gene delivery. Acta Pharm Sin B. 2018;8(2):165-177. doi:10.1016/j.apsb.2018.01.007

32. Iturrioz-Rodríguez N, Correa-Duarte MA, Fanarraga ML. Controlled drug delivery systems for cancer based on mesoporous silica nanoparticles. Int $J$ Nanomedicine. 2019;14:3389-3401. doi:10.2147/IJN.S198848

33. Kesse S, Boakye-Yiadom KO, Ochete BO, et al. Mesoporous silica nanomaterials: versatile nanocarriers for cancer theranostics and drug and gene delivery. Pharmaceutics. 2019;11(2):77. doi:10.3390/ pharmaceutics 11020077 
34. Zhang W, Liu M, Liu A, et al. Advances in functionalized mesoporous silica nanoparticles for tumor targeted drug delivery and theranostics. Curr Pharm Des. 2017;23(23):3367-3382. doi:10.2174/1381612822666161025153619

35. Kresge C, Leonowicz ME, Roth WJ, et al. Ordered mesoporous molecular sieves synthesized by a liquid-crystal template mechanism. Nature. 1992;359:710-712. doi:10.1038/359710a0

36. Summerlin N, Qu Z, Pujara N, et al. Colloidal mesoporous silica nanoparticles enhance the biological activity of resveratrol. Colloids Surf $B$ Biointerfaces. 2016;144:1-7. doi:10.1016/j.colsurfb. 2016.03.076

37. Lin C, Zhu W, Li J, et al. An efficient route to rapidly access silica materials with differently ordered mesostructures through counteranion exchange. Chemistry. 2013;19(31):10146-10149. doi:10.1002/ chem.201300597

38. Saikia D, Deka JR, Wu CE, et al. $\mathrm{pH}$ responsive selective protein adsorption by carboxylic acid functionalized large pore mesoporous silica nanoparticles SBA-1. Mater Sci Eng C Mater Biol Appl. 2019;94:344-356. doi:10.1016/j.msec.2018.09.043

39. Zhao D, Feng J, Huo Q, et al. Triblock copolymer syntheses of mesoporous silica with periodic 50 to 300 angstrom pores. Science. 1998;279(5350):548-552. doi:10.1126/science.279.5350.548

40. Rivera-Muñoz EM, Huirache-Acuña R. Sol gel-derived SBA-16 mesoporous material. Int J Mol Sci. 2010;11(9):3069-3086. doi:10.3390/ijms11093069

41. Jadhav NV, Vavia PR. Dodecylamine template-based hexagonal mesoporous silica (HMS) as a carrier for improved oral delivery of fenofibrate. AAPS PharmSciTech. 2017;18(7):2764-2773 doi:10.1208/s12249-017-0761-x

42. Mellinas C, Ramos M, Grau-Atienza A, et al. Biodegradable Poly( $\varepsilon-$ Caprolactone) active films loaded with MSU-X mesoporous silica for the release of $\alpha$-Tocopherol. Polymers (Basel). 2020;12(1):137. doi:10.3390/polym12010137

43. Stöber W, Fink A, Bohn E. Controlled growth of monodisperse silica spheres in the micron size range. $J$ Colloid Interface Sci. 1968;26:62-69. doi:10.1016/0021-9797(68)90272-5

44. Li Z, Zhang Y, Feng N. Mesoporous silica nanoparticles: synthesis, classification, drug loading, pharmacokinetics, biocompatibility, and application in drug delivery. Expert Opin Drug Deliv. 2019;16 (3):219-237. doi:10.1080/17425247.2019.1575806

45. Narayan R, Nayak UY, Raichur AM, et al. Mesoporous silica nanoparticles: a comprehensive review on synthesis and recent advances. Pharmaceutics. 2018;10(3):118-166. doi:10.3390/ pharmaceutics 10030118

46. Yi Z, Dumee LF, Garvey CJ, et al. A new insight into growth mechanism and kinetics of mesoporous silica nanoparticles by in situ small angle X-ray scattering. Langmuir. 2015;31 (30):8478-8487. doi:10.1021/acs.langmuir.5b01637

47. Hollamby MJ, Borisova D, Brown P, et al. Growth of mesoporous silica nanoparticles monitored by time-resolved small-angle neutron scattering. Langmuir. 2012;28(9):4425-4433. doi:10.1021/la203097x

48. Yamamoto E, Shimojima A, Wada H, et al. Mesoporous silica nanoparticles with dispersibility in organic solvents and their versatile surface modification. Langmuir. 2020;36(20):5571-5578. doi:10.1021/acs.langmuir.0c00729

49. Mehmood Y, Khan IU, Shahzad Y, et al. Amino-decorated mesoporous silica nanoparticles for controlled sofosbuvir delivery. Eur J Pharm Sci. 2020;143:105184. doi:10.1016/j.ejps.2019.105184

50. He Y, Luo L, Liang S, et al. Amino-functionalized mesoporous silica nanoparticles as efficient carriers for anticancer drug delivery. J Biomater Appl. 2017;32(4):524-532. doi:10.1177/0885328 217724638

51. Wang B, Zhang K, Wang J, et al. Poly(amidoamine)-modified mesoporous silica nanoparticles as a mucoadhesive drug delivery system for potential bladder cancer therapy. Colloids Surf B Biointerfaces. 2020;189:110832. doi:10.1016/j.colsurfb.2020.110832
52. Choi E, Kim S. Surface $\mathrm{pH}$ buffering to promote degradation of mesoporous silica nanoparticles under a physiological condition. $J$ Colloid Interface Sci. 2019;533:463-470. doi:10.1016/j. jcis.2018.08.088

53. He K, Li J, Shen Y, et al. pH-Responsive polyelectrolyte coated gadolinium oxide-doped mesoporous silica nanoparticles (Gd2O3@MSNs) for synergistic drug delivery and magnetic resonance imaging enhancement. J Mater Chem B Mater Biol Med. 2019;7(43):6840-6854. doi:10.1039/c9tb01654f

54. Shah PV, Rajput SJ. Facile synthesis of chitosan capped mesoporous silica nanoparticles: a $\mathrm{pH}$ responsive smart delivery platform for raloxifene hydrochloride. AAPS PharmSciTech. 2018;19 (3):1344-1357. doi:10.1208/s12249-017-0949-0

55. Chen C, Sun W, Wang X, et al. pH-responsive nanoreservoirs based on hyaluronic acid end-capped mesoporous silica nanoparticles for targeted drug delivery. Int J Biol Macromol. 2018;111:1106-1115. doi:10.1016/j.ijbiomac.2018.01.093

56. Mishra S, Hook JM, Nebhani L. Priming the pores of mesoporous silica nanoparticles with an in-built RAFT agent for anchoring a thermally responsive polymer. Microporous Mesoporous Mater. 2019;277:60-69. doi:10.1016/j.micromeso.2018.10.012

57. Liu J, Li Y, Zhao M, et al. Redox-responsive hollow mesoporous silica nanoparticles constructed via host-guest interactions for controllable drug release. J Biomater Sci Polym Ed. 2020;31(4):472-490. doi:10.1080/09205063.2019.1700601

58. Yang Y, Lin Y, Di D, et al. Gold nanoparticle-gated mesoporous silica as redox-triggered drug delivery for chemo-photothermal synergistic therapy. J Colloid Interface Sci. 2017;508:323-331. doi:10.1016/j. jcis.2017.08.050

59. Chen X, Sun $\mathrm{H}, \mathrm{Hu} \mathrm{J}$, et al. Transferrin gated mesoporous silica nanoparticles for redox-responsive and targeted drug delivery. Colloids Surf B Biointerfaces. 2017;152:77-84. doi:10.1016/j. colsurfb.2017.01.010

60. Chen L, Zhou X, Nie W, et al. Multifunctional redox-responsive mesoporous silica nanoparticles for efficient targeting drug delivery and magnetic resonance imaging. ACS Appl Mater Interfaces. 2016;8 (49):33829-33841. doi:10.1021/acsami.6b11802

61. Kumar B, Kulanthaive S, Mondal A, et al. Mesoporous silica nanoparticle based enzyme responsive system for colon specific drug delivery through guar gum capping. Colloids Surf B Biointerfaces. 2017;150:352-361. doi:10.1016/j. colsurfb.2016.10.049

62. Liu Y, Ding X, Li J, et al. Enzyme responsive drug delivery system based on mesoporous silica nanoparticles for tumor therapy in vivo. Nanotechnology. 2015;26(14):145102. doi:10.1088/0957-4484/26/14/ 145102

63. Guisasola E, Asín L, Beola L, et al. Beyond traditional hyperthermia: in vivo cancer treatment with magnetic-responsive mesoporous silica nanocarriers. ACS Appl Mater Interfaces. 2018;10(15):12518-12525. doi:10.1021/acsami.8b02398

64. Li E, Yang Y, Hao G, et al. Multifunctional magnetic mesoporous silica nanoagents for in vivo enzyme-responsive drug delivery and MR imaging. Nanotheranostics. 2018;2(3):233-242. doi:10.7150/ ntno. 25565

65. Yu X, Zhu Y. Preparation of magnetic mesoporous silica nanoparticles as a multifunctional platform for potential drug delivery and hyperthermia. Sci Technol Adv Mater. 2016;17(1):229-238. doi:10.1080/14686996.2016.1178055

66. Li X, Xie C, Xia $\mathrm{H}$, et al. $\mathrm{pH}$ and ultrasound dual-responsive polydopamine-coated mesoporous silica nanoparticles for controlled drug delivery. Langmuir. 2018;34(34):9974-9981. doi:10.1021/acs. langmuir.8b01091

67. Wang W, Wang Y, Wang Y, et al. Redox/pH dual stimuli-responsive $\mathrm{ZnO}$ QDs-gated mesoporous silica nanoparticles as carriers in cancer therapy. IET Nanobiotechnol. 2019;13(6):640-649. doi:10.1049/ietnbt.2019.0031 
68. Vallet-Regi M, Rámila A, Del Real RP, et al. A new property of MCM-41:drugdelivery system. Chem Mater. 2001;13(2):308-311. doi:10.1021/cm0011559

69. Lu J, Liong M, Li Z, et al. Biocompatibility, biodistribution, and drug delivery efficiency of mesoporous silica nanoparticles for cancer therapy in animals. Small. 2010;6(16):1794-1805. doi:10.1002/ smll.201000538

70. Wu M, Li X, Guo Q, et al. Magnetic mesoporous silica nanoparticles-aided dual MR/NIRF imaging to identify macrophage enrichment in atherosclerotic plaques. Nanomedicine. 2020;32:102330. doi:10.1016/j.nano.2020.102330

71. Huang Y, Li T, Gao W, et al. Platelet-derived nanomotor coated balloon for atherosclerosis combination therapy. $J$ Mater Chem B Mater Biol Med. 2020;8(26):5765-5775. doi:10.1039/ d0tb00789g

72. Xu W, Zhang S, Zhou Q, et al. VHPKQHR peptide modified magnetic mesoporous nanoparticles for MRI detection of atherosclerosis lesions. Artif Cells Nanomed Biotechnol. 2019;47(1):2440-2448. doi:10.1080/21691401.2019.1626411

73. Wang L, Feng M, Li Y, et al. Fabrication of superparamagnetic nano-silica@ quercetin-encapsulated PLGA nanocomposite: potential application for cardiovascular diseases. J Photochem Photobiol B. 2019;196:111508. doi:10.1016/j.jphotobiol.2019.05.005

74. Jeong HJ, Yoo RJ, Kim JK, et al. Macrophage cell tracking PET imaging using mesoporous silica nanoparticles via in vivo bioorthog onal F-18 labeling. Biomaterials. 2019;199:32-39. doi:10.1016/j. biomaterials.2019.01.043

75. Ji R, Li X, Zhou C, et al. Identifying macrophage enrichment in atherosclerotic plaques by targeting dual-modal US imaging/MRI based on biodegradable Fe-doped hollow silica nanospheres conjugated with anti-CD68 antibody. Nanoscale. 2018;10 (43):20246-20255. doi:10.1039/c8nr04703k

76. Zhang J, Nie S, Martinez-Zaguilan R, et al. Formulation, characteristics and antiatherogenic bioactivities of CD36-targeted epigallocatechin gallate (EGCG)-loaded nanoparticles. $J$ Nutr Biochem. 2016;30:14-23. doi:10.1016/j.jnutbio.2015.11.001

77. Robbins CS, Hilgendorf I, Weber GF, et al. Local proliferation dominates lesional macrophage accumulation in atherosclerosis. Nat Med. 2013;19(9):1166-1172. doi:10.1038/nm.3258

78. Tabas I. Macrophage death and defective inflammation resolution in atherosclerosis. Nat Rev Immunol. 2010;10(1):36-46. doi:10.1038/ nri2675
79. Liu X, Sun J. Endothelial cells dysfunction induced by silica nanoparticles through oxidative stress via JNK/P53 and NF-kappaB pathways. Biomaterials. 2010;31(32):8198-8209. doi:10.1016/j. biomaterials.2010.07.069

80. Liu X, Xue Y, Ding T, et al. Enhancement of proinflammatory and procoagulant responses to silica particles by monocyte-endothelial cell interactions. Part Fibre Toxicol. 2012;9:36. doi:10.1186/1743-8977-9-36

81. Guo C, Xia Y, Niu P, et al. Silica nanoparticles induce oxidative stress, inflammation, and endothelial dysfunction in vitro via activation of the MAPK/Nrf2 pathway and nuclear factor- $\mathrm{KB}$ signaling. Int J Nanomedicine. 2015:1463-1477. doi:10.2147/IJN.S76114.

82. Petrick L, Rosenblat M, Paland N, et al. Silicon dioxide nanoparticles increase macrophage atherogenicity: stimulation of cellular cytotoxicity, oxidative stress, and triglycerides accumulation. Environ Toxicol. 2016;31(6):713-723. doi:10.1002/tox.22084

83. Guo C, Ma R, Liu X, et al. Silica nanoparticles promote oxLDL-induced macrophage lipid accumulation and apoptosis via endoplasmic reticulum stress signaling. Sci Total Environ. 2018;631-632:570-579. doi:10.1016/j.scitotenv.2018.02.312

84. Yang L, Zang G, Li J, et al. Cell-derived biomimetic nanoparticles as a novel drug delivery system for atherosclerosis: predecessors and perspectives. Regen Biomater. 2020;7(4):349-358. doi:10.1093/rb/ rbaa019

85. Xuan MJ, Shao JX, Zhao J, et al. Red blood cell membranes cloaked magnetic mesoporous silica nanoparticles applied for cancer therapy. Angew Chem Int Ed Engl. 2018;57(21):6049-6053. doi:10.1002/ anie.201712996

86. Xuan MJ, Shao JX, Dai LR, et al. Macrophage cell membrane camoufl aged mesoporous silica nanocapsules for in vivo cancer therapy. $A d v$ Healthc Mater. 2015;4(11):1645-1652. doi:10.1002/adhm.201500129

87. Kankala RK, Han YH, Na J, et al. Nanoarchitectured structure and surface biofunctionality of mesoporous silica nanoparticles. $A d v$ Mater. 2020;32(23). doi:10.1002/adma.201907035

88. Wang Y, Zhang K, Li TH, et al. Macrophage membrane functionalized biomimetic nanoparticles for targeted anti-atherosclerosis applications. Theranostics. 2021;11(1):164-180. doi:10.7150/thno.47841

89. Song Y, Huang Z, Liu X, et al. Platelet membrane-coated nanoparticle-mediated targeting delivery of Rapamycin blocks atherosclerotic plaque development and stabilizes plaque in apolipoprotein E-deficient (ApoE-/-) mice. Nanomedicine. 2019;15(1):13-24. doi:10.1016/j.nano.2018.08.002
International Journal of Nanomedicine

\section{Publish your work in this journal}

The International Journal of Nanomedicine is an international, peerreviewed journal focusing on the application of nanotechnology in diagnostics, therapeutics, and drug delivery systems throughout the biomedical field. This journal is indexed on PubMed Central, MedLine, CAS, SciSearch ${ }^{\mathbb{R}}$, Current Contents ${ }^{\mathbb{R}} /$ Clinical Medicine, $^{2}$

\section{Dovepress}

Journal Citation Reports/Science Edition, EMBase, Scopus and the Elsevier Bibliographic databases. The manuscript management system is completely online and includes a very quick and fair peer-review system, which is all easy to use. Visit http://www.dovepress.com/ testimonials.php to read real quotes from published authors. 